\title{
Making sense of violence: a study of narrative meaning
}

\author{
Rachel Louise Shaw \\ Department of Health Sciences, University of Leicester, 22-28 Princess Road West, Leicester LE1 6TP, \\ $U K$
}

\begin{abstract}
Dramatized violence has been a feature of entertainment in western civilization throughout history. The function of film violence is explored and compared to violence encountered in real life. The role of narrative in individuals' meaning-making processes is also investigated. Six adults were individually interviewed using a semi-structured schedule and narrative analysis was implemented. The findings revealed that real life violence is experientially distinct from film violence but narrative was found to be central to participants' quest for the meaning of violence in both contexts. The narrative framework of violence and whether it is justifiable were fundamental to participants' understanding. The function of violent film was found to be multifaceted: it can teach viewers about the consequences of violence; it allows them to speculate about their own and others' reactions to violence; and it provides an opportunity to experience something which is ordinarily outside of our experience in order to satisfy our human existential needs. Qualitative Research in Psychology 2004; 1:
\end{abstract} $131-151$

Key words: film violence; meaning-making; narrative; phenomenology; real life violence

\section{Introduction}

Encountering violence in real life can be a devastating event which leaves victims with lasting emotional and physical scars. Paradoxically, watching violence via the medium of film has become an established pastime in modern western civilization. Evidence that violence has been a part of entertainment throughout history confirms that this is not a post nineteenth century phenomenon (Bloch, 1998; Bok, 1998; Warner, 1998). The overwhelming historical presence of violence in folklore, mythical

Correspondence: Rachel Louise Shaw, Department of Health Sciences, University of Leicester, 22-28 Princess Road West, Leicester LE1 6TP, UK.

E-mail:rls25@le.ac.uk 
legends, nursery rhymes, lullabies, literature, theatre and film suggests that violence which is experienced receptively through a dramatized medium has some kind of allure. One common feature of these forms of popular culture stands out; each portrays representations of violence within the context of a narrative. Telling stories is also a favourite human pursuit. More than that, 'the narrative is present at all times, in all places, in all societies; the history of narrative begins with the history of mankind; there does not exist, and never has existed, a people without narratives' (Barthes, 1966, cited in Polkinghorne, 1988: 14).

Since its introduction into mainstream psychology by figures like Theodore Sarbin (1986) and Jerome Bruner (1990), narrative has had a limited impact in specialist areas, such as personality and human development (McAdams, 1985), psychotherapy (e.g., Mair, 1989) and health psychology (e.g., Atkinson, 1997; Crossley, 1999). Conventional psychology has not previously applied the philosophy of narrative to the study of media violence. Previous research in the discipline of mass communications has come close by attempting to explain audience interpretations and behaviours when watching violent film in terms of genre, realism, film conventions and boundary testing (e.g., Barker and Brooks, 1998; Buckingham, 1996; Hill, 1997; Morrison et al., 1999). The bulk of psychological literature though has overlooked the significance of why we are attracted to violent film and how we make sense of the images portrayed, instead focusing upon the effects of being exposed to media violence (e.g., Cumberbatch and Howitt, 1989; Paik and Comstock, 1994). The research described in this paper is therefore attempting something new by approaching the subject of film violence from a narrative analytic stance.
Film was chosen as the medium of dramatized violence that this research focused on because it is one of the most pervasive entertainment media in contemporary culture. Individuals were invited to reflect upon their experiences of violent film as well as their experiences as victims of violence in real life or witnesses of violent events. The apparent diversity of these two experiential phenomena was explored. Secondly, this research asked what is the role of narrative in individuals' meaning-making process, and finally, it aimed to answer the question what is the function of film violence?

\section{Methodology}

This is an inquiry into the meanings of violent experiences. Husserl (1936) drew our attention to the significance of meaning-making by stating that human behaviour, experience, and scientific achievements are all grounded in the making of meaning. As such, any study of human experience must be concerned with meanings and how they are attributed to everyday life by adopting a phenomenologically sensitive approach as proposed by Giorgi (1970). Donald Polkinghorne's (1988) study of narrative meaning is employed in this research. Polkinghorne states that meanings are not concrete because we are continuously reconstructing them. Furthermore each of us is aware only of our own unique realm of meaning. This makes the study of meaning dependent upon selfreflection. Self-reflection, however, can only reveal the outcomes of meaning-making processes and not the processes themselves. In order to begin to grasp the complex meanings communicated by human actors we must turn to language 
because 'language is commensurate with meaning' (Polkinghorne, 1988: 7). We use language every day to negotiate and renegotiate meanings and the most natural way to achieve this is through 'the mediation of narrative interpretation' (Bruner, 1990: 67). Hence to effectively study the 'lived experience' (Heidegger, 1962) of individuals' encounters with violence in real life and via film we must analyse their use of narrative, both in the ways they attribute meanings to their experiences and in the ways they tell their 'stories' of experiencing violence. To achieve this aim a study of narrative meaning was conducted.

\section{Participants}

Six individuals were interviewed. Smith (2003) recommends that for a study which aims to explore subjective experience, a small sample size made up of five or six interviews with one or more individuals is used. Such a project is concerned with revealing the nuances of idiosyncratic experiences in participants' accounts rather than making representative claims. Six participants were interviewed once in this study and were asked to tell their stories of violent experiences. As described below, the analysis was concerned not only with individuals' experiential accounts, it was also involved in revealing the meanings, structure and function of the narratives used by participants. A single interview with each participant was therefore sufficient for the focus of this study. Interviews were conducted using a semi-structured interview schedule with open-ended questions and participants were encouraged to speak freely about their experiences (Mishler, 1986). Recruitment was through either the Victims of Crime Support Scheme or the local cinema. The project was designed to investigate experiences of violent film from the perspective of individuals who enjoy watching popular film. At the same time, it aimed to explore the experience of being a victim or witness of violence in real life. The choice of agencies through which to recruit participants directly reflected this dual objective. Each participant involved in the study described experiencing violent film in a meaningful way and also recounted a real life event which they felt was violent. Whether their interview focused on film or real life or both depended upon which was most significant to participants when telling their stories. Some participants spoke mainly about film, whereas some concentrated on their real life experience of being a victim of violence. Other participants gave equal time in their interviews to violence experienced via film and that encountered in real life. All participants were aged 18 or over both because it was adult experiences which were of interest and also in order to comply with the ' 18 ' rating given by the British Board of Film Classification to many films which contain violent scenes.

\section{Interview schedule}

Participants were asked to name any films they had watched which they believed contained scenes of violence and then to talk about their responses to those scenes and films as a whole. The interviewer prompted individuals to describe why they believed particular scenes to be violent, how they reacted to them at the time and how they felt about violent film more generally. The interviewer did not make any suggestions about which films should be defined as violent; this choice was left open to participants. As a result, films from different genres were discussed by each individual, including a drama based on a true story, The Accused; a crime thriller, Seven; a 'cult classic' about heroin addiction, Trainspotting; a reworking of a literary 
classic, William Shakespeare's Romeo and Juliet; and the 'new brutalism' films, Natural Born Killers, Reservoir Dogs and Pulp Fiction. Allowing the participants to select which films they discussed was a crucial aspect to the project. The point of the exercise was to ascertain what participants felt was violent in the hope that the retelling of their experience would enable them to verbalize what they actually defined as violent and how they were able to make it meaningful.

Participants were then asked to talk about any encounters with violence they had experienced in real life. Again the definition of a violent encounter was left up to them and different stories unfolded including being a victim of an armed robbery, witnessing a mob crime in Africa, and conducting a police chase of an escaped convict. The interviewer asked participants to describe how the incident happened, how they reacted to it, what action they took, and how they felt then and now.

The questions were designed to elicit participants' narratives but also to answer more direct questions about how they experienced the violence at the centre of their stories. As a result the opening questions were similar to those used in traditional narrative research, for example, 'tell me about any films you have experienced which you thought were violent' or 'have you ever experienced anything violent in your own life?'. Supplementary questions were asked once a participant was in the midst of a story in order to obtain more detail about their experiences, for example, 'what kind of emotions went through your mind at that point of the film?' or 'what did you think of straight away after it happened?'. The researcher told participants they could withdraw from the study at any point during or after the interview, that their data would be stored confidentially and that their names would be changed if their data were used in any published work. Interviews were tape-recorded and transcribed for analysis.

\section{Analysis}

The method of analysis employed in this study is an analysis of narrative meaning (Polkinghorne, 1988) which has a dual purpose: to reveal the narrative structures at work in individuals' meaning-making processes; and to reveal the narrative devices employed by individuals in retelling their experiences of violence. The pragmatic approach adopted borrows aspects of technique and purpose from narrative analysis as described by Crossley (2000) and Murray (2003) and from interpretative phenomenological analysis (Smith et al., 1999). Smith's stages of coding for an interpretative phenomenological analysis are implemented initially to explore participants' experiences. Before an analysis of participants' use of narrative can be conducted we first need to establish the nature of their experience. The phenomenological aspect of Smith's approach will help to achieve this goal. Crossley's narrative analysis will then help to discern which, if any, narrative structures helped participants to make sense of their experiences of violence. Crossley aims to identify the narrative tone present in the accounts and the imagery used by participants. Another useful step advocated by Crossley is for the analyst to conduct an analysis of their own personal narrative alongside the analysis of participants' accounts. In other contexts this would be referred to as reflexive analysis (Mulkay, 1985). Reflexivity is becoming increasingly important in psychology as in other areas of the social sciences (Smith, 1994; Finlay and Gough, 2003) and can ensure that the analyst is 
capable of achieving a genuine and honest analysis. Finally, Murray's conception of narrative analysis allows the analyst to encapsulate the wider scheme of narrative function within the account as a whole. The aim of Murray's narrative analysis is 'to reveal the underlying structure of narrative accounts that shape not only the way we account for our actions and those of others but also our very identity' (Murray, 2003: 130). This will help the analyst to identify the narrative structures used by participants in recounting their experiences of violence. These results will then be synthesized.

\section{Findings}

The results of the preliminary analysis of themes will be presented alongside the identification of narrative structures within participants' meaning-making processes. The evidence of narrative devices at work in participants' language will then be discussed together with the concluding remarks about the analysis. Before we move on to the main analysis the researcher presents a brief reflexive analysis of her own narrative.

\section{A reflexive analysis of my personal narrative}

As the researcher I acted as interviewer, analyst and author of this research. At the time these interviews were conducted I was a woman in my midtwenties with little experience of violence in real life. I was however interested in violent film, hence the topic of this research. In order to explore the issues of violent film comprehensively I believed it was necessary to also investigate individuals' experiences of violence in real life, particularly considering the connection between film and real life that had already been created in the public consciousness by media coverage of films such as Natural Born Killers and events such as the Dunblane shootings.

Sometimes I found the accounts of real life violence offered by participants distressing. The confidence evident in their retelling however and the familiar style of the narrative devices employed assisted my reading and understanding of what had happened; I could respond empathically both to the detail of the events participants described and to the ways it made them feel. This was a challenging experience for someone with no clinical or counselling training but one that I was able to manage by actively listening to participants' stories and also by being aware of how I felt on hearing them. I was more at ease when discussing film violence because that was an experience with which I was familiar. However, this called upon the different technique of selfmonitoring my own presuppositions. As a student of psychology with an interest in film I was intellectually familiar with film theories of audience behaviour as well as psychology's part in the perpetuation of the media effects discourse which dominated the public domain. As a result I had to consciously stop myself from contributing to participants' debates about media violence and their responses to violent film in order to enable them to reveal the nature of their experiences using their own language.

Aspects of my personal narrative may be evident in the written analysis of the data presented in this paper and it was certainly evident during the interpretative act of analysis. This is a great benefit of qualitative research methods; they allow the 'researcher as person' into the research process in order to get closer to the 'participant as 
person', in order to gain an insider's perspective of their experiences.

\section{Themes and narrative structures}

Initially the themes emerging from the data were separated according to whether they related to film violence or real life violence. This enabled participants' experiences of film violence to be represented in terms of responses to violent scenes, justifications for violent actions within scenes, portraits of characters involved in violence, expectations and publicity surrounding notoriously violent films and the effects of violent media more generally. Similar themes were elicited in relation to experiences of real life violence, such as emotional responses to violence, rationalizations for violence and beliefs about violence. In addition when participants spoke of real life encounters with violence they experienced a struggle to come to terms with it, and some participants found the anticipation of what could happen more threatening than what actually did happen.

The themes which emerged from the data that are related to the narrative analysis are presented. These include the justifications of film violence, character portraits in film, the functions of film violence, and experiencing violence in real life.

\section{Justifications of film violence.}

Frequently in their accounts of violent films participants automatically began to justify the presence of violence. After having discussed several films with Danny which he believed contained violent scenes I asked him about whether he believed such violence had a function.

Rachel$^{1}$ : Do you think that has a function, that violence in films has any kind of function?

Danny $^{2}$ : As I said it depends I mean if it's not done properly then it's obviously there just you know, for a bit of surprise and shock maybe, but there are occasions where as I say it's necessary for the plot I mean if you're trying to show a situation where the life is violent then you've got to show, you know, violence, as it really is. So in that case you can't understand, I don't know, gang land New York or something without showing the violence that's in there, so yes I think on most occasions it is, it is justified and needs to be shown.

At the time of Katie's interview Natural Born Killers was in the news (e.g., Whitworth, 1999) because there had been a case of alleged copy-cat crime in the USA. I asked Katie if she had seen this film so we could engage in a discussion about violent films of a controversial nature. Katie had seen Natural Born Killers and knew of the issues; she then began to discuss other films with equally violent reputations.

Rachel: Have you seen Natural Born Killers?

Katie: I saw it with the same group of friends I saw Pulp Fiction with and I found it harder than Pulp Fiction. We had a debate afterwards and a friend found Pulp Fiction so disturbing that she walked out but had no problem with Natural Born Killers. There seemed to be so much violence. It seemed like an MTV video style. I was concerned about how glamorous it made the perpetrators look. I don't have a problem with violence in films if it's legitimate within the scheme of the plot. I have less of a problem with something like Reservoir Dogs because it's about the on-going injuries of one person. A lot of people had trouble with Tim Roth's character and the pool of blood getting bigger, but I thought that was realistic and how it is. I have less of a problem with that than something like The Terminator where life is very cheap and people just get blown away two a penny.

Danny's justification for violent scenes in films was connected to the stories they told. He was unsure about violence that is used to manipulate the audience for shocking effect, for example, but believed that sometimes stories of a particular subculture require representations of violence for them to be told effectively. Katie too was explicitly concerned with 'the plot' in her assess- 
ment of justified violence. In the screenplay of Natural Born Killers Quentin Tarantino deliberately manipulated the traditional linear plot in order to create an atmosphere of chaos which Oliver Stone brought to the screen with the MTV-style camera work. This problematizes Katie's reading of Natural Born Killers, making it hard to deal with. Probably the most elemental of traditional narrative features is the linear plotline. Hence, when this is taken away, chaos thrives, making a coherent understanding of events in the film extremely difficult to achieve.

Katie's account then unfolds to reveal the more implicit significance of realism in her judgement of whether violence can be justifiably portrayed in film. The violence of Tim Roth's slow death in Reservoir Dogs is rationalized by Katie because of its realism. This finding supports Annette Hill's (2001) conclusions about women who enjoy the 'new brutalist' films like those in Tarantino's repertoire. Hill reports an interview excerpt almost identical to Katie's in which a participant, Jill, described Tim Roth's 'bleeding to death' as 'a reminder of just how bad it can be to be shot' (Hill, 2001: 139). Jill appreciated the challenge of painful scenes, strong narratives and characterization, such as those portrayed in Reservoir Dogs, and preferred this to films like Die Hard 'where you just accept the violence as a matter of course' (Hill, 2001: 139). Hill's findings also support Danny's and Katie's notion that the context of the film's plot is central to viewers' responses to violent scenes.

Diane saw Reservoir Dogs too but unlike Katie was unable to justify its violence.

Rachel: And what do you think about violence in fiction films?

Diane: It depends, it's like swearing, sometimes that's the only way you can portray a particular character or scene, the only way you can get the story across. [..] Some of the Tarantino films, Reservoir Dogs, that was two hours of mindless violence, so in that case there was no need for it. It wasn't entertaining, it was a waste of film budget. There wasn't any need for the violence, I didn't get it. I can remember the ear-cutting scene and I remember a lot of shooting. It does tell a story but I don't know what it was. [laughs] When I came away I just saw blood and no storyline.

Rachel: Does the story make a difference then? Diane: Sometimes violence helps to get a story across. The Accused, you had to show the rape because that's what the whole film is about. The whole film is based around that girl and what she went through and that's what the film was about. That was particularly disturbing, I didn't like that very much because it could happen to me. It's a woman and it's the kind of thing that could happen to me, I didn't like it.

From her account Diane appeared to have been equally disturbed by both films she mentioned. However, her reaction to The Accused was tolerated because it told a tale of something which 'could happen'. The screening of the rape was according to Diane valid because she could justify its presence within the narrative; if we had not seen the rape we would not understand the context of Jodie Foster's character's pain and suffering. Schlesinger et al. (1992) also investigated women's responses to The Accused and found that women relate to film violence either as 'the recreation of a painful or dangerous personal experience' or as an approximation of a feared event (Schlesinger et al., 1992: 164). In her interview Diane recounted some of her experiences of being in a violent relationship. Although her abuse was not described as sexual, it was suffered at the hands of a man. Her reaction therefore could represent both a painful memory and a feared yet imaginable and realistic event. This female response has been found to differ from the equivalent male reaction to a rape scene (Schlesinger et al., 1998). In this later study Schlesinger 
and colleagues explored men's responses to the scene in Basic Instinct where Michael Douglas' Detective Nick Curran rapes Jeanne Tripplehorn's character, Dr Beth Garner. Men did not condone rape but were found to relate more easily to the male protagonist. This is an example of how the position of the viewer, due to gender in this case, can influence an individual's reading and justification of a violent scene within a particular narrative.

Diane's view of the justification of violence in Reservoir Dogs was diametrically opposed to Katie's. On one level this forcefully illustrates the significance of idiosyncratic beliefs in the process of making sense of violence in film; Diane described the violence in Reservoir Dogs as 'mindless' and was unable to justify it. However, they both used the same mechanism when they found justification of violence possible: realism enabled Katie to justify the long and bloody death of Tim Roth's character; and Diane's justification of the rape scene was due to the fact that it showed, in her interpretation, a realistic event. So even though the meanings attached to individual experiences remained unique, there were similarities in the processes through which meaning was attributed based on the context of realism. Hence the narrative framework of the violence portrayed was central to both Katie and Diane in their interpretations of film violence.

\section{Character portraits in film.}

Most stories involve human actors interacting with each other as a series of events unfold. Violent films are no exception to this rule but the roles of the characters appeared to be of particular consequence to the ways in which participants made sense of violence portrayed. Simon dis- cussed several films portraying characters from the Mafia and described a scene in Casino which was difficult to watch. In spite of that Simon bought the video to watch at his own leisure and later went on to describe the importance of characters in films of this genre.

Simon: I've seen Casino, Donnie Brasco and Goodfellas, three of the most violent ones. Casino is the one I'd pick out as having violence I couldn't watch, but I bought it on video. The violence was necessary to the plot to portray the lives of people in the Mafia. [..]

Rachel: What was it in Casino that you found difficult?

Simon: The scene that was difficult to watch was the one where they're torturing a bloke for information and they put his head in a vice and they start tightening it. My eyes were wincing when I watched it at the cinema. I have watched it since on video and it's not an easy scene to watch at all.

[..]

Rachel: What emotions went through your mind when they were closing the vice and you were thinking that's the sort of thing that could happen to me? [referring to a previous comment made by Simon]

Simon: I was struck by how evil these people are and the awful things they were doing and I realised that these were probably the methods they used and, what makes them do that to another human being? It gives you an insight into the way the Mafia works, it adds to the realism.

Simon was animated when retelling his emotional response to the 'vice scene' in Casino; his appreciation for the film as a craft was evident. He was a self-confessed 'film fan' which is perhaps the reason he was able to endure such 'difficult' viewing whilst retaining a feeling of enjoyment. Engaging with a film was important to Simon and for that to occur he had to understand the characters within the context of the story. The significance of the characters in Simon's process of making sense of violent film was even clearer in 
his account of watching Seven and Trainspotting.

Rachel: Do you think for something to be violent it has to be physical contact?

Simon: There's psychological violence so it doesn't necessarily have to be physical. I saw Seven and that film, and Trainspotting as well, I enjoyed them. Sometimes the point of the film isn't for you to enjoy it but I always use the word 'enjoy' because if you like it and you were entertained by it, you enjoyed it. It's not as if it's putting the thought in your mind to go and do what you've seen. It was psychological violence in Seven, I couldn't sleep after seeing that film. That's the first film I've seen where I really thought about the characters, how are they going to be now, because they'd been that well portrayed during the film you really thought how are they going to deal with it, that incident that happens at the end is going to be with them for the rest of their lives. It fucked my head up a bit, because it was psychological violence, Kevin Spacey knew what he'd done and he knew Brad Pitt wanted to kill him and he wanted him to. Pitt was having his revenge and he knew it would be with him for the rest of his life but he knew he had to do it. It was psychological violence. With Trainspotting I wasn't really affected by the violence but it was Renton. At the beginning I felt empathy for him and it was quite light hearted, they're doing daft things even when he swaps the videos over but that's the crucial point where everything starts to go wrong. Then he gives drugs to Tommy and you see what he's capable of doing. Then he catches something from the cat and that bloke says the cat's fine and everyone laughed but I thought that was beyond laughter, it didn't lighten the mood at all. It wasn't funny at all, it didn't detract from the seriousness at all.

Seven and Trainspotting were linked by Simon because they portrayed 'psychological violence'. In Seven it was against its central 'hero' character and in the case of Trainspotting its central character was the perpetrator. Simon's diverse interpretations of this psychological violence may indeed be due to this difference. In watching Seven Simon had taken to heart the conditions in which Brad Pitt's and Morgan Freeman's detective characters battled against the serial killer, played by Kevin Spacey. Simon cared for Brad Pitt's character and so the anguish and passion portrayed by Pitt in his shooting of Kevin Spacey's serial killer was justified or even expected because of the final twist of the film which revealed the murder of his (unbeknown to him) pregnant wife. His description of Trainspotting however revealed a feeling of betrayal which was difficult to interpret on face value. Simon was unable to make sense of Renton's (Ewan McGregor) behaviour because he felt isolated by the intended joke about the cat. Tommy (Kevin McKidd) contracted the HIV virus after being introduced to heroin by Renton. As a result of Renton's actions Tommy lost his girlfriend and became depressed. He then fell ill and died because he caught an infection from his neglected cat. These facts are narrated by Renton during the funeral scene and his tone of voice signifies irony and humour at the manner in which Tommy died. It then became clear that it was Simon's inability to see the joke, like Diane's inability to get the story, that resulted in his quest for meaning being unsatisfied. Simon's account revealed that he felt empathy for Renton but on this occasion his understanding of the character backfired. Many mainstream Hollywood films have borrowed their narrative structure from mythology and folklore which means that in most cases audiences are able to recognize formulaic aspects of film, such as the hero/villain dichotomy described by Vladimir Propp (1968). This well established narrative feature has been turned on its head in Trainspotting which makes Simon's meaning-making process particularly difficult. Believable characters were key to his interpretation of Trainspotting but its rejection of traditional roles causes problems for Simon. The torment 
that Brad Pitt's character endured justified his murder of Kevin Spacey's character. The attempt made by Renton to have the last laugh about his friend's death cannot be justified because, according to Simon, Renton killed Tommy. The meanings Simon attributed to his two experiences of psychological violence were quite distinct. It is due to this marked contrast in Simon's interpretation of the films that the mechanism he employed to make sense of film violence was successful in one case and not in the other. The detailed portrait of the characters in Seven enabled Simon to understand the motivation, background, and justification for the characters' actions within the film's narrative. The difference in Trainspotting is that Simon cannot justify Renton's behaviour. Despite his initial empathy for Renton, Simon believed that Renton was suddenly unveiled not as a vulnerable victim of circumstance but as an uncaring individual willing to sacrifice a friend's well-being for the sake of a joke. This revelation that Renton was not the person Simon believed him to be led to the prevailing meaninglessness of the scene. In essence a viewer requires access to the traits and flaws of film characters to provide a means through which understanding and therefore justification and meaning can be reached.

\section{The function of film violence.}

Throughout his struggles with Seven and Trainspotting, Simon maintained that he enjoyed them. At the beginning of the extract presented he said that 'sometimes the point of the film isn't for you to enjoy it'. What then is the point of watching violent film? Katie, like Simon, enjoyed going to the cinema but she believed there was more to be gained from watching violent film than mere entertainment. Katie enjoyed the opportunity for social intercourse, for cultural stimulation and the post hoc philosophizing about the nature of the human condition.

Rachel: What makes you want to go and see a film?

Katie: If I've got information about the director of the film or the cast and there's people whose films you've seen and you've enjoyed. I'm not that discriminating, if there's a week when there's films that I might not enjoy as much as others I have seen I would still go. Even if I haven't enjoyed the film I enjoy the discussion afterwards so it is still part of an evening's entertainment. I tend to go to the cinema with my partner who is also interested in films and it would be rare for us to just go out and not comment about it afterwards, it would be unusual. I normally go once a week, three times a fortnight.

Similarly, Danny enjoyed the opportunity to discover 'the other side of life' when watching violent film which is reflected in his assessment of it.

Rachel: Can you think of the film that stands out in your memory as being the most violent film you've seen?

Danny: Erm, Reservoir Dogs probably something like that. As I said in there the violence was the film. There really, I mean, as I said I'm not too keen on films which just use it to grab the audience but I don't think that was done in such a gratuitous way. It was more just showing how things can be and I think that's the whole point now of getting a glimpse of the other side of life that you don't see very often. So although it was violence, it was, I think it was done in a more or less sensible way. I mean you saw the consequences of it which is I think that's the main thing that people worry about violence for that it's showing, like you see The A Team they're there blasting away with their guns and everybody sort of stands up pats themselves off and strolls off for a cup of tea whereas in that you know you actually saw that if you go around shooting things people get hurt I mean if you see the amount of blood coming out of Tim Roth that's enough to put you off firing a gun in the first place so. 
Danny has no time for gratuitous violence but appreciated that violence which is realistic and which shows the consequences of people's violent actions has a role. Danny was hopeful that being exposed to realistic violence would teach viewers to be aware of what will happen if violence is used. Peter also believed that representations of violence are justified and serve the purpose of reflecting the tragedy that violence can create. Peter was not a regular cinema-goer but had recently watched William Shakespeare's Romeo and Juliet starring Leonardo DiCaprio and Claire Danes. Baz Luhrmann's film takes place in a modern day 'Verona Beach' with street gun battles and spectacular explosions set against fast paced camera work and music.

Rachel: What did you think about the violence in Romeo and Juliet?

Peter: I thought the violence was valid because it showed the senseless results of groundless family bickerings and it shows the tragedy of young men killing each other for no reason, except for their fathers' arguments. The violence was justified because it was in proportion to the message that was being portrayed.

Peter's and Danny's belief that realistically portrayed violence could have an educational function was grounded in experience. Peter was a police inspector and Danny trained in the army but left because he was disillusioned with violence. For them, film violence had the function of teaching the audience about real life violence and its consequences. A multifaceted function of violent film has emerged from the data presented: experiencing violence via film allows individuals to learn about violence in a pragmatic sense; it allows viewers to speculate about human nature and the lengths different people will go to when faced with a violent situation; and it provides an opportunity to experience some- thing which is outside our usual everyday existence.

Experiencing violence in real life.

For participants in this study the experience of violence was not limited to that portrayed on screen. As a police officer Peter had encountered violence in real life more frequently than most. He spoke of fights as 'bread and butter' and described the experience of chasing an escaped convict as being a particularly dangerous situation. He had finished a story about being called to deal with an armed, suicidal man who had attempted to stab Peter and his fellow officers when they broke down the locked door of the room in which he was hiding. To me, this was a violent and dangerous situation, hence my question, but for Peter that was not the case.

Rachel: Can you think of an example that wasn't quite as bad as that?

Peter: That wasn't bad. It's incredible it's often when things don't happen that you get more frightened, when things happen you can get on with it and deal with it. We're not actually trained to cope with it, not sufficiently anyway. When you expect something to happen and you know you're dealing with someone dangerous, that's when it's frightening. Another example then is when I was after a prison escapee and it was reported that he had a gun. I found this man and he did have a gun. This was before the time of armed police officers. I chased this man and he dropped the gun. Later my colleagues told me that he also had a knife that he threw away as I was approaching him, I never saw this knife. Anyway I caught him in the end. This was a frightening situation because this man was intimidating, he was only small, relatively, but it was his personality. When you're dealing with someone who has no conscience there is no restriction on his misbehaviour and the potential of something happening is always there, even when you are interviewing them, that's when it's frightening. The actuality is less frightening than the anticipation. 
Peter's account bears a resemblance to Simon's description of psychological violence; it was the mental reaction to a potentially violent situation rather than an actual physical attack which Peter believed to be one of the most violent experiences he encountered as a police officer. The notion of 'anticipation' which Peter refers to as frightening highlights the unpredictability of violence. This fear of the unknown, of being afraid of what could happen, is present in several participants' stories of violence. Katie felt that she had never been a victim of violence herself but described an event which was particularly disturbing because she was in a foreign situation, both literally and experientially.

Rachel: Have you ever experienced anything violent yourself in real life?

Katie: I have never had any violence against myself. I have seen violent situations when I was younger, fights in pubs. The most violent thing I have seen in my life was on a bus in [Africa]. I lived there for two years. [..]

Rachel: What happened?

Katie: There was a thief on the bus and because the country is poor, pick-pocketing is usually dealt with by mobs. Someone was kicked and beaten unconscious and left in the corner of the bus and then the bus was driven to the police station and he was thrown out. That was really, really disturbing.

Rachel: Can you describe what happened?

Katie: A man got on a bus as if he was a passenger but he wasn't, he wanted to go through peoples' bags and it was found out what he was doing very quickly. Rather than the police being called a mob thing took over. That was the culture there though so it wasn't as surprising that it happened. It was very shocking because it was outside my experience. He was a couple of seats in front of me and he fell to the floor and people kept kicking him and then all the people who had been involved just went back to their seats on the bus and the driver drove to the police station and said 'this is a thief'. It sounds crazy telling it but in the context of life there it was normal. [..] I can't compare it to a similar thing happening in England because it isn't a parallel situation. It was so beyond my experience that it was very shocking. I felt sick when it happened, shaky, sick, shocked. I tried to stand up and say something but the first language in [that country] isn't English but there was nothing I could have done, I was powerless in the situation.

This story of violence in a foreign country stresses the significance of cultural differences when attributing meaning to violent events. Previously we saw how important the plot was to understanding violent scenes in films; this account reveals an equivalent need for contextualization in real life. The cultural code in Britain does not condone violent mob behaviour in any situation which meant Katie did not understand the readiness of the passengers on the bus to get involved in beating the pickpocket. Katie's shock at witnessing the attack was equalled by her shock in response to the passengers' behaviour during the attack and their calm return to normality after it. Katie was left disturbed, shocked, and feeling ill without any available means of making sense of what happened. Her fellow passengers closed off any route to rationalization for Katie by reacting indifferently to what she felt was a violent and unjust attack. In effect, Katie was denied access to the narrative framework of this event because she was isolated by culture; the context necessary to understand the motivation behind the behaviour of the characters in her story was not available. As an outsider, Katie's path to understanding was frustrated, resulting in her feeling of powerlessness.

Violence in familiar circumstances can also be difficult to deal with. Andrea told of an armed robbery in the off licence she managed. The thieves were armed with knives and in the interview Andrea had said earlier, 'I've got a thing about knives I don't like knives, I think people pull them out too quickly and that scares me', which 
points towards the lasting effect of her experience.

Rachel: Have you ever experienced anything violent in your own life?

Andrea: Yes I've had an experience. I was working in an off licence I was manageress for a while and two guys came in with knives and basically we got robbed. It's been a while since I've talked about this actually it was a few years ago. I was serving and two guys came in earlier and they didn't buy anything, my boyfriend was in the back which was lucky, I'd go in, have a brew and we'd have a chat. There's a bell on the door so I know if there's someone in the shop. So I go in and there's this guy there and he says can you tell me which wine this is and such and such a thing so I left the counter which I shouldn't have done really and he just pushed me into the back of the room and this other guy who was looking at chocolate and things on the other side came back in, they didn't know my boyfriend was in the back so that took them by surprise and they were just like shouting 'where's the safe?', 'empty this', 'you hold this bag', and we ended up being locked in this stockroom we had a stockroom with just a bolt where all the beer was kept and we ended up being locked in there. It sounds dead dramatic doesn't it. They made out of the front of the shop and about two minutes later, it felt like about ten, fifteen, but it was only a couple of minutes later we heard the bell go and we were like 'we're in here'. And I was crying and you know all that.[..]

That was quite shocking. I had to have two weeks off work and I ended up leaving work through it. I didn't want to go back in the shop. After the two weeks holiday I went back in and I just hated the job, hated it. It was during the day, four o'clock in the afternoon.

Rachel: What did you think of straight away after it happened?

Andrea: I felt stupid because I'd left the counter, and should we have done it differently and David [Andrea's boyfriend] was saying 'I should have just hit him' you know. We were just saying what we should have done different, if we'd have been near the panic button, I don't know. But one of them had a knife so and we couldn't understand why nobody was coming in the shop. It was just, it felt really surreal afterwards and everyone was fussing over us and the company was worried about me. It was just a really weird time for me that. It was about two years ago now. I still go past the shop I always look in the shop, always. Really weird. I don't think about it everyday or anything like that. A couple of weeks later, I'd only been with my boyfriend about two months so it was like 'can you believe that happened to us?', we were like buzzing about it but not you know, I wouldn't like it to happen again but it happened and we dealt with it. We were in the paper and everything we were local celebrities. Everyone was like that [making a gun out of her hands] 'stick 'em up!' all our friends and everything. I think if I'd have been on my own it would have been completely different, I'd have been a nervous wreck.

A struggle to come to terms with what happened is evident in Andrea's account. Immediately after the event Andrea was unable to continue working at the shop and at the time of the interview, two years later, she found that it was still current in her mind despite her claim that it was a closed chapter ('I don't think about it everyday or anything like that'). In her account Andrea painted a nostalgic picture of the routine that she shared with her boyfriend. She was in a familiar setting, she was responsible and confident. When the thieves robbed the shop though they violated this space that she shared with her boyfriend and they not only stole the money from the till, they also deprived her of a job and her confidence. Andrea's rationalization for the robbery was simply that the thieves were on drugs. Her rationalization of the way she reacted told more about Andrea's great effort to make sense of what had happened. Andrea was critical of her decision to leave the counter which turned out to be a ploy by the thieves, she felt degraded by their demands, she was concerned that she could have prevented it and was embarrassed about crying. There is no room, in Andrea's eyes, for these failings despite the fact that she was being threatened at knife point and that she was 
undoubtedly in shock. The legacy of this event was that Andrea was constantly reminded of what happened, which indicates that the powerlessness she felt at the time had never been overcome by attributing meaning to the event. However, she was able to glean something of use from the experience. Andrea recounted that she and her boyfriend were 'buzzing' after what she described as a 'dead dramatic' and 'surreal' event; in spite of the shame she felt about her response she was able to see that in fact she and her boyfriend had achieved something together. The way Andrea described this feeling was as if she and her boyfriend were heroes in an adventure ('stick 'em up!'); in spite of the fear and in spite of the danger, they successfully dealt with the experience and came through the other side with an exciting story to tell. This seemed like a 'surreal' event to Andrea because the only other context in which she had witnessed such behaviour was via the big screen. She therefore used the 'dramatic' narrative conventions of film to explain her heroic 'buzz'. This sense of achievement was significant to Andrea because it was only through the discovery that she and her boyfriend had gained something by enduring this event that she was able to attribute meaning to it and account for what happened.

\section{Narrative devices in participants' accounts}

The strategies employed by participants to make sense of their experiences of violence resemble narrative features of storytelling; the story itself as a whole, the characters' motivations, and the cultural context of events were each illustrated as crucial in participants' accounts. It is also possible to identify places in the text where participants have employed narrative devices to tell their stories.
The accounts of real life encounters with violence told by Peter, Katie, and Andrea each began with information that sets the scene. For example, Peter introduced his story using the phrase, 'another example is when I was after a prison escapee...' This is an attention-grabbing device that immediately draws the listener in by advertising the content of the story to follow. This technique is traditionally used by novelists to capture the reader's imagination and to persuade them to continue reading. Katie's initial short description of the violence she observed, 'there was a thief on a bus...', acts in a similar way. She described the event in short, sharp phrases to stress the impact it had upon her. A great deal of information is compacted into this brief description; already the listener is aware that a man was beaten unconscious, it was because he was a thief, and it was a very disturbing event to witness. Katie then provides further detail of her emotional response to what happened in answer to the question 'can you describe what happened?'. Another mechanism Katie adopted to contextualize her narrative account was to offer information that will help the listener understand the impact of the event, "That was the culture there though. . ' This contextualization of Katie's encounter with violence conveyed a dual message: that Katie was shocked and disturbed by what she witnessed because it was 'outside her experience'; but also her shock was perpetuated because it was 'normal' in that country for pick-pockets to be 'dealt with by mobs'.

Andrea's account also began with a high impact description of the event, 'I was working in an off licence ... and basically we got robbed'. She then went on to tell the story in more detail providing further contextual information where necessary, 'my boyfriend was in the back so that took them 
by surprise'. Andrea's choice of words reflects the message she wished to portray and her ability to employ narrative techniques to do so was evident. For instance, repeating what the actors in the story said using the present tense, whether or not it is a verbatim account, made the event feel more contemporaneous. Similarly, in recounting the event, Andrea stated, 'It sounds dead dramatic doesn't it', which illustrates her awareness of the effect of the way she told the story on the listener's reading of what happened. The simple use of words like 'surreal', Katie's description of someone being 'kicked and beaten unconscious and left in the corner of the bus', and Peter's fear of 'someone who has no conscience', each relayed powerful images. Participants' narrative tone when recounting their experiences of violence was animated and excited yet deeply effective in portraying the intense responses they each had to the violence they encountered. This enables the listener to imagine the scene, to empathize with the storyteller and to understand the significance of the event.

These narrative devices are also employed by film makers. The accounts presented of participants' experiences of violence via film revealed that it was precisely these narrative techniques which allowed viewers to make sense of scenes of violence. Characters' motivations, the story told by a film, and the aspects of violence portrayed which enabled viewers to justify its presence, such as realism, helped them to make sense of their experience of watching violent film. In exactly the same way, the context in real life in which violence occurred and the motivation of the perpetrators assisted victims and witnesses of violence participating in this study to understand why the violence happened. This is particularly significant because it shows that whether violence is experienced in real life or via film the same mechanisms are implemented to make sense of it. This does not mean the experiential boundaries between real life and film are blurred; the contrary has been shown to be the case. It does mean though that we use precisely the same meaning-making process when attributing meaning to violence in real life as violence in film. Real life events are experienced and made sense of through their narrative structure; they are interpreted in exactly the same way as a film or some other narrative form. Also, in recounting their encounters with violence in real life, participants used the same devices employed in existing types of narrative, such as novels and films, to make their experience intelligible to the listener. In doing this participants confirmed that they depended upon their own constructions of narrative structures to both make sense of their violent encounters and to retell them in a comprehensive manner. Hence narrative is the primary function in our quest for the meaning of violence whatever its context.

Worthy of note is a small but significant difference in tone between participants' narratives about real life violence and film violence. Applying a narrative structure to real life violent events performed an organizational function, in that it allowed individuals to think about violence in a structured and organized way which helped them to come to terms with it. The case was different with film violence. Although narrative was found to be equally significant to the meaning-making process in film as in real life, it appeared to have a more argumentative, defensive tone. This difference can be attributed to the 'effects model' (Gauntlett, 2001) which dominates the way film violence is construed in modern society. The negative connotations of violent 
film and the concern that people exposed to it will be 'affected' and subsequently become more violent dominates the public consciousness of the modern western world. This is not a new phenomenon.

'This simple image of direct effects draws its power from a deep reservoir of social fear and dogma which first formed in the mid-nineteenth century as commentators began to link the social costs of modernity with the proliferation of new forms of popular entertainment. Then, as now, the perceived disorders of the present were often counterposed against an idealised image of the past.' (Murdock, 2001: 151)

The effects model defines viewing violent film as an anti-social behaviour which increases society's ills by creating violent people. Society expects law-abiding citizens to be repulsed by violent films, a notion which is perpetuated by accusatory media articles which blame films like $R e$ servoir Dogs and Natural Born Killers for violent crime (Gauntlett, 2001). It is not surprising therefore that fans of violent film feel they require some kind of defence for pursuing their chosen pastime. The argumentative structure of participants' dialogue when describing their experiences of film violence demonstrates the power of the effects model and its infiltration into mainstream society. As a result the cultivation of this dominant discourse demands justification for the very act of watching violent films before we even consider the possibility of enjoying them.

\section{Discussion}

The findings of this research have revealed the significance of narrative in individuals' experience of violence. Watching violent film is an experience which can be difficult and participants have shown the necessity of drawing upon narrative structures to make sense of such portrayals of violence. Encountering violence in real life had, as expected, a greater impact on participants than being exposed to violence on screen. Furthermore participants' accounts illustrated the difficulties with which they were confronted when attempting to make sense of violence in real life. Often the motivation of the perpetrators of violence was unclear or their actions existed outside of participants' ordinary everyday experience. It was therefore the absence of a readymade narrative structure and the consequent anticipation of the unknown which left participants feeling powerless in their struggle to explicate the occurrence of violence in real life.

We have already seen that meaning is crucial in understanding human experience. Viktor Frankl's work on logotherapy however, which he developed during and partly because of his suffering whilst a prisoner of war in Nazi concentration camps, places 'the will to meaning' at the centre of human existence.

'Man's search for meaning is the primary motivation in his life and not a 'secondary rationalisation' of instinctual drives. This meaning is unique and specific in that it must and can be fulfilled by him alone; only then does it achieve a significance which will satisfy his own will to meaning.' (Frankl, 1984: 121)

The human ability to reframe or translate experience as contingent narrative is the method through which this meaning is attributed to our life events. This is evident in participants' accounts. Their implementation of narrative devices reveals on one level the usefulness of narrative in attributing meaning. However the centrality of narrative structure in individuals' meaning-making processes is powerfully demonstrated in the event of meaning being frustrated. When an event remains mean- 
ingless, participants have shown that it is due to a lack of narrative context. In the process of making sense of an event we find ourselves reliving it, going over the detail, and searching for mitigating circumstances that can account for what happened (Bruner, 1990). The act of telling another what has occurred offers the opportunity to frame the experience within a story. The pervasiveness of narratives in everyday life means that we are familiar with their form and are readily able to provide storied accounts of our own and others' behaviours (Polkinghorne, 1988). These contingent narratives provide a route to meaning.

Our attraction to narrative forms can explain the success of film in contemporary culture. What remains difficult to grasp though is the appeal of experiencing violence through this receptive channel. One way of explaining this behaviour, proposed by Annette Hill (1997), is that we use violent film for boundary-testing, that is to test the boundaries of what we are willing and able to endure. Hill describes film viewers, like Simon, who purchase a video of a violent film like Casino or Reservoir Dogs so that they can watch the disturbing 'vice scene' or 'ear-cutting scene' over and over in order to test their reactions to it and discover whether they could, after repeated viewing, cope with it better. An awareness of others' responses as well as our own when viewing violence, together with the techniques used by film makers to 'hype up' violent films, contribute to our expectations of them and subsequently influence the level of satisfaction gained through watching them. Our motivation in choosing to watch a film which we know or expect will contain scenes of a violent nature is not explained by this however. The functions revealed by participants have gone beyond Hill's theory of boundary testing; we are not simply attempting to test ourselves but are essentially attempting to make sense of uniquely human acts of violence. The educational possibilities of portraying the consequences of violence in a realistic manner were also identified in this research as a function of violent film. A more fundamental question remains however; what can be gained through experiencing violence via a dramatized medium? To answer this question we begin with Rollo May's theory of the aesthetic ecstasy of dramatized violence. To illustrate his theory May described a scene in Herman Melville's 1891 novel, Billy Budd, Foretopman. This story is about justice and the injustice of punishment. May described the scene where in response to the perceived unjust charge of mutiny Billy was 'seized by sudden rage in his verbal impotence' (May, 1972: 170) and hit the Master at Arms with all his rage, killing him outright.

'When this act of sheer violence occurs on stage or screen, a sigh of relief goes through the audience [original emphasis]. We feel that the violence fits the situation. It is aesthetically called for; nothing less would have sufficed. Violence makes complete the otherwise incomplete aesthetic Gestalt. At that point there is for the audience the experience of the ecstasy of violence in aesthetic terms.' (May, 1972: 170)

Dramatized violence that is 'called for' in this manner is felt deeply by the audience; likewise, according to this study's participants, film violence such as Brad Pitt's murder of Kevin Spacey in Seven is justified by its context: but what is its function? May believed that through the tragedy of such violence we experience our own mortality, which enables us to transcend, for a moment, our relatively banal existence. A crucial distinction made by May is confirmed by participants' interpretations and rationalizations of film violence. May stated that for the aesthetic ecstasy of violence to 
be achieved the violence must be an integral part of the drama and not inserted for shock value, horror or titillation. Again we return to the importance of narrative in individuals' attempts to make sense of violence experienced via film. This may not be a straightforward explanation that applies equally to all viewers of violent film. There may be issues of gender, for example, which influence the degree to which the aesthetic ecstasy of violence is at work in an individual's experience of dramatized violence. Schlesinger et al.'s (1998) work falls within with society's stereotype of the powerful, 'macho man'; they concluded that men preferred the 'new brutalist' violent films such as Reservoir Dogs and found them more satisfying than formulaic action films such as Under Siege. If this is not surprising then what would the stereotypical passive, feminine woman make of such in-your-face violence? Annette Hill's (2001) study of women's enjoyment of 'new brutalist' films asked that very question.

'I want to show that this attraction [to violent films] is not based on deviancy or amorality, but rather it is an attraction to the aesthetics of film, the range of emotional and physical responses to watching film, and the experience of testing responses to violent cinema.' (Hill, 2001: 136)

Hill's findings revealed that the women in her study enjoyed the 'new brutalism' genre of film because it offered something new and because it invited feelings of fear, anger, excitement, laughter and surprise. A useful development of this work would be to investigate the aesthetic ecstasy of violence according to gender and across different cultural roles, taking into consideration the effect of power dynamics within individuals' experiences and also the ways in which they make sense of violent film.

Erich Fromm's notion of 'existential needs' (Fromm, 1973: 26) provides a further explanation for participants' identifications of possible functions of violent film. According to Fromm, uniquely human passions such as the need for love, tenderness and freedom as well as the lust for destruction, sadism, and power, help to satisfy the existential needs that are rooted within the very conditions of human existence. Katie's belief that violent film prompts a pseudophilosophical assessment of human nature suggests that our process of meaning-making may be achieved through an understanding of these existential needs. Similarly, Danny's and Simon's interpretations of violent film as an opportunity to go beyond our ordinary existence support the notion that Fromm's existential needs can indeed be satisfied vicariously.

\section{Conclusion}

This research asked how individuals react to and cope with violence portrayed in film and encountered in real life to ascertain if there are any similarities between these apparently diverse experiences. It also asked what role is played by narrative in individuals' attempts to attach meaning to their experiences of violence. Finally it asked what is the function of violent film. The answers provided are based in participants' data and in the literature. In answer to the first question, individuals are able to make sense of their experiences of violence both via film and in real life through interpreting the narrative structure provided. When meaning is frustrated it is due to the lack of a narrative framework in which to place events. This is more likely to occur in real life because in film a readymade story is usually, although not always, accessible. This leads directly to the second question. Narrative was found to be central to participants' meaning-making processes. If an encounter with violence in real life or a violent film was not contextualized by 
narrative it was extremely difficult to gain any sense from it. However, in the act of retelling events, apparently meaningless experiences were framed within a contingent narrative which subsequently led to understanding. This significance of narrative continues in the answer to the third and final question. The function of violent film is dependent on both the story it tells and the narrative devices it employs in telling it. Only if film violence can be rationalized and considered crucial to the story can it serve a purpose. That function is to go beyond our ordinary experience and to live for a moment outside of our relatively mundane existence. Violence is embedded within human culture and through the aesthetic Gestalt we can experience the 'ecstasy of violence' vicariously via coherent narratives and are able to satisfy our specifically human existential needs.

\section{Films cited}

The Accused. 1984: Director, Jonathan Kaplan.

Basic Instinct. 1991: Director, Paul Verhoeven.

Casino. 1995: Director, Martin Scorsese.

Die Hard. 1988: Director, John McTiernan.

Donnie Brasco. 1997: Director, Mike Newell.

Goodfellas . 1990: Director, Martin Scorsese. Natural Born Killers. 1994: Director, Oliver Stone.

Pulp Fiction. 1994: Director, Quentin Tarantino.

Reservoir Dogs. 1992: Director, Quentin Tarantino.

Seven. 1995: Director, David Fincher.

The Terminator. 1984: Director, James Cameron.

Trainspotting. 1996: Director, Danny Boyle.
William Shakespeare's Romeo and Juliet. 1996: Director, Baz Luhrmann.

\section{Acknowledgements}

I would like to thank the participants for sharing their experiences, also David Hiles and Kevin Wright for their guidance and support when conducting and writing up this research.

\section{Notes}

1. Interviewer

2. The names of all participants have been changed.

\section{References}

Atkinson, P. 1997: Narrative turn or blind alley? Qualitative Health Research 7, 325-44.

Barker, M. and Brooks, K. 1998: Knowing audiences: Judge Dredd, its friends, fans and foes. Luton: University of Luton Press.

Barthes, R. 1966: Introduction to the structural analysis of the narrative. Occasional Paper, Centre for Contemporary Cultural Studies, University of Birmingham, stencilled.

Bloch, M. 1998: The presence of violence in religion. In Goldstein, J.H. editor, Why we watch: the attractions of violent entertainment. New York, NY: Oxford University Press.

Bok, S. 1998: Mayhem: violence as public entertainment. Reading, MA: Perseus Books.

Bruner, J. 1990: Acts of meanings. Cambridge, MA: Harvard University Press.

Buckingham, D. 1996: Moving images: understanding children's emotional responses to television. Manchester: Manchester University Press. 
Crossley, M. 1999: Stories of illness and trauma survival: liberation or repression? Social Science and Medicine 48, 1685-95.

2000: Introducing narrative psychology: self, trauma and the construction of meaning. Buckingham: Open University Press.

Cumberbatch, G. and Howitt, D. 1989: A measure of uncertainty: the research evidence. (A Broadcasting Standards Monograph.) London: John Libbey and Co Ltd.

Finlay, L. and Gough, B. 2003: Reflexivity: $a$ practical guide for researchers in health and social sciences. Oxford: Blackwell Publishing.

Frankl, V.E. 1984: Man's search for meaning: revised and updated. New York, NY: Washington Square Press.

Fromm, E. 1973: The anatomy of human destructiveness. Reprinted, 1990. London: Penguin.

Gauntlett, D. 2001: The worrying influence of 'media effects' studies. In Barker, M. and Petley, J., editors, Ill effects: the media/ violence debate, second edition. London: Routledge.

Giorgi, A. 1970: Psychology as a human science: a phenomenologically based approach. New York, NY: Harper and Row Publishers incorporated.

Heidegger, M. 1962: Being and time, seventh edition. London: SCM Press. (Translated by Macquarrie, J. and Robinson, E.)

Hill, A. 1997: Shocking entertainment: viewer responses to violent movies. Luton: University of Luton Press/John Libbey.

2001: 'Looks like it hurts': women's responses to shocking entertainment. In Barker, M. and Petley, J., editors, Ill effects: the media/violence debate, second edition. London: Routledge.

Husserl, E. 1936: The crisis of European sciences and transcendental phenomenology. Evanston, IL: Northwestern University Press. (Translated by Carr, D., 1970.)
Mair, M. 1989: Between psychology and psychotherapy: a poetics of experience. London: Routledge.

May, R. 1972: Power and innocence: a search for the sources of violence. New York, NY: W.W. Norton and Co Inc.

McAdams, D. 1985: Power, intimacy, and the life story: personological inquiries into identity. New York, NY: Guilford.

Melville, H. 1891: Billy Budd, Foretopman. In Melville, H., Four short novels. New York, NY: Bantam Books. (Reprinted, 1959.)

Mishler, E.G. 1986: Research interviewing: context and narrative. Cambridge, MA: Harvard University Press.

Morrison, D., McGregor, B., Svennevig, M. and Firmstone, J. 1999: Defining violence: the search for understanding. Luton: University of Luton Press.

Mulkay, M. 1985: The word and the world. London: Allen and Unwin.

Murdock, G. 2001: Reservoirs of dogma: an archaeology of popular anxieties. In Barker, M. and Petley, J., editors, Ill effects: the media/violence debate, second edition. London: Routledge.

Murray, M. 2003: Narrative psychology. In Smith, J.A., editor, Qualitative psychology: a practical guide to research methods. London: Sage.

Paik H. and Comstock, G. 1994: The effects of television violence on antisocial behaviour: a meta-analysis. Communication Research 21, 516-46.

Polkinghorne, D.E. 1988: Narrative knowing and human sciences. New York, NY: State University of New York Press.

Propp, V. 1968: Morphology of the folktale, second edition. Austin, TX: University of Texas Press. (Translated by Scott, L.)

Sarbin, T., editor, 1986: The storied nature of human conduct. New York, NY: Praeger.

Schlesinger, P., Dobash, R.E., Dobash, R.P. and Weaver, C.K. 1992: Women viewing violence. London: BFI Publishing. 
Schlesinger, P., Haynes, R., Boyle, R. and McNair, B. 1998: Men viewing violence. London: British Standards Commission.

Smith, J.A. 1994: Towards reflexive practice: engaging participants as co-researchers or co-analysts in psychological inquiry. Journal of Community and Applied Social Psychology 4, 253-60.

2003: Interpretative phenomenological analysis. In Smith, J.A., editor, Qualitative psychology: a practical guide to research methods. London: Sage.
Smith, J.A., Jarman, M. and Osborn, M. 1999: Doing interpretative phenomenological analysis. In Murray, M. and Chamberlain, K., editors, Qualitative health psychology. London: Sage.

Warner, M. 1998: No go the bogeyman: scaring, lulling and making mock. London: Chatto and Windus.

Whitworth, D. 1999: Film violence put in the dock. The Times 9th March, 14.

\footnotetext{
About the author

Rachel Shaw is a psychologist working in the Department of Health Sciences at the University of Leicester. Her current work is funded by the ESRC Research Methods Programme and involves the development and evaluation of systematic review methodology for qualitative evidence. She completed her PhD at De Montfort University in 2001 which investigated individuals' experiences of violence both via the medium of popular film and directly in real life. She then worked on two health psychology projects, about women's experiences of breastfeeding, at Coventry University. Rachel has a keen interest in sensitive and controversial experiences of health and illness, narrative and discourse, and the development of synthesis methods for qualitative evidence.
} 